\title{
Usefulness of Combinations of Vertex-Degree Weighted Path Indices and Elements of a Universal Matrix
}

\author{
Anton Perdih \\ Faculty of Chemistry and Chemical Technology, University of Ljubljana (retired) \\ Večna pot 113, 1000 Ljubljana, Slovenia \\ *Corresponding author: E-mail: a.perdih@gmail.com
}

Received: 06-19-2019

\begin{abstract}
The mutually optimized combinations of vertex-degree weighted path indices and the vertex-degree vertex-distance weighted elements of the Universal matrix were applied in the way of $\mathrm{TI}_{\text {new }}=\sum \mathrm{k}_{\mathrm{N}} \times \mathbf{P N}\left(\mathrm{a}_{\mathrm{N}}, \mathrm{b}_{\mathrm{N}}, \ldots\right)+\mathrm{k}_{\mathrm{ij}} \times \mathbf{u}_{\mathrm{ij}}\left(\mathrm{a}_{\mathrm{ij}}, \mathrm{b}_{\mathrm{ij}}, \mathrm{c}_{\mathrm{ij}}\right)$. They were correlated to the boiling points of octanes. Using the mutually optimized combination of vertex-degree weighted path indices $\mathbf{P} 2\left(\mathrm{a}_{2}, \mathrm{~b}_{2}, \mathrm{c}_{2}\right), \mathbf{P} 3\left(\mathrm{a}_{3}, \mathrm{~b}_{3}, \mathrm{c}_{3}, \mathrm{~d}_{3}\right)$, and $\mathbf{P} 4\left(\mathrm{a}_{4}, \mathrm{~b}_{4}, \mathrm{c}_{4}, \mathrm{~d}_{4}, \mathrm{e}_{4}\right)$ there was observed $R=0.99950$. When in addition to $\mathbf{P 2}\left(\mathrm{a}_{2}, \mathrm{~b}_{2}, \mathrm{c}_{2}\right), \mathbf{P} 3\left(\mathrm{a}_{3}, \mathrm{~b}_{3}, \mathrm{c}_{3}, \mathrm{~d}_{3}\right)$, and $\mathbf{P 4}\left(\mathrm{a}_{4}, \mathrm{~b}_{4}, \mathrm{c}_{4}, \mathrm{~d}_{4}, \mathrm{e}_{4}\right)$ also $\mathbf{P 1}\left(\mathrm{a}_{1}, \mathrm{~b}_{1}\right)$ or $\mathbf{u}_{72}\left(\mathrm{a}_{72}, \mathrm{~b}_{72}, \mathrm{c}_{72}\right)$ or $\mathbf{u}_{76}\left(\mathrm{a}_{76}, \mathrm{~b}_{76}, \mathrm{c}_{76}\right)$ or $\mathbf{u}_{62}\left(\mathrm{a}_{62}, \mathrm{~b}_{62}, \mathrm{c}_{62}\right)$ or $\mathbf{u}_{74}\left(\mathrm{a}_{74}, \mathrm{~b}_{74}, \mathrm{c}_{74}\right)$ or $\mathbf{u}_{52}\left(\mathrm{a}_{52}, \mathrm{~b}_{52}, \mathrm{c}_{52}\right)$ have been applied, then the goodnesses of up to $R=0.99988, S=0.098, I C=98.5 \%$ have been observed.

The mutually optimized combinations of vertex-degree weighted path indices and the vertex-degree vertex-distance weighted elements of the Universal matrix are promising indices also for other physicochemical properties of octanes.
\end{abstract}

Keywords: Boiling point; Octanes; Matrix elements; Path indices; Structural interpretation

\section{Introduction}

Path indices ${ }^{1,2}$ were first used by Wiener ${ }^{3,4}$ and together with the connectivity indices ${ }^{5-8}$ they are being used by numerous other authors. The path indices ${ }^{1,2}$ and the connectivity indices ${ }^{5-8}$ were previously considered to be two different groups of indices. It has been, however, shown ${ }^{9}$ that both groups of them are parts of the vertex-degree weighted path indices $\mathbf{P N}(a, b, \ldots)$. The mutually optimized combinations of vertex-degree weighted path indices gave rise in the case of 29 physicochemical properties of octanes to $R(\mathbf{P 1 . . P 4})>0.9 .^{9}$ In the mutually optimized combinations with some of the elements of the Universal matrix the values were $R=0.994$ or higher.

Ivanciuc ${ }^{10,11}$ described the Dval matrix and presented its characteristics. His approach was developed into the Universal matrix by using the vertex-degree vertex-distance weighted elements. The indices derived from it were tested for their usefulness as descriptors of a number of physicochemical properties of alkanes in general and of octanes in particular. ${ }^{12,13}$ For the definition of the Universal matrix and its elements see Appendix 3 in ref. ${ }^{13}$ The mutually optimized combinations of the vertex-degree vertex-distance weighted elements of the Universal matrix were tested for their usefulness as descriptors of a number of physicochemical properties of octanes. ${ }^{14}$

Here is presented the approach using the mutually optimized combinations of vertex-degree weighted path indices and the vertex-degree vertex-distance weighted elements of the Universal matrix. The correlations to the boiling points (BP) of octanes are used to illustrate the usefulness of the approach, which is generally applicable. These combinations allow to be made also some structural interpretations of indices involved in them.

\section{Definitions, Data and Methods}

Vertex-degree weighted path indices are defined as $\mathbf{P N}\left(\mathrm{a}_{\mathrm{N}}, \mathrm{b}_{\mathrm{N}}, \ldots\right)=\sum \mathrm{v}_{\mathrm{i}}^{\mathrm{a}} \times \mathrm{v}_{\mathrm{j}}^{\mathrm{b}} \times \ldots$, where $\mathrm{v}_{\mathrm{i}}, \mathrm{v}_{\mathrm{j}}$, etc. are the vertex degrees. ${ }^{9}$ The vertex-degree vertex-distance weighted elements of the Universal matrix are defined as $\mathbf{u}_{\mathrm{ij}}\left(\mathrm{a}_{\mathrm{ij}}, \mathrm{b}_{\mathrm{ij}}, \mathrm{c}_{\mathrm{ij}}\right)$ $=\mathrm{v}_{\mathrm{i}}^{\mathrm{a}} \times \mathrm{v}_{\mathrm{j}}{ }^{\mathrm{b}} \times \mathrm{d}_{\mathrm{ij}}{ }^{\mathrm{c}}$, where $\mathrm{v}_{\mathrm{i}}$ and $\mathrm{v}_{\mathrm{j}}$ are the vertex degrees and $\mathrm{d}_{\mathrm{ij}}{ }^{\mathrm{c}}$ is the distance between the vertices $i$ and $j .{ }^{14}$ In the text, they are often presented in a shorthand form as $\mathbf{P N}$ and $\mathbf{u}_{\mathrm{ij}}$, respectively. 
The mutual optimization of these indices and matrix elements is performed in the way of $\mathrm{TI}_{\text {new }}=\sum \mathrm{k}_{\mathrm{N}} \times \mathbf{P N}\left(\mathrm{a}_{\mathrm{N}}\right.$, $\left.b_{N}, ..\right)+k_{i j} \times u_{i j}\left(a_{i j}, b_{i j}, c_{i j}\right)$ using one or more of the vertex-degree weighted path indices $\mathbf{P N}\left(\mathrm{a}_{\mathrm{N}}, \mathrm{b}_{\mathrm{N}}, \ldots\right)$ and/or the vertex-degree vertex-distance weighted elements of the Universal matrix $\mathbf{u}_{\mathrm{ij}}\left(\mathrm{a}_{\mathrm{ij}}, \mathrm{b}_{\mathrm{ij}}, \mathrm{c}_{\mathrm{ij}}\right)$, where $\Sigma\left|\mathrm{k}_{\mathrm{N}}\right|+\left|\mathrm{k}_{\mathrm{ij}}\right|=1$. The indication of mutual optimization is presented in the text or tables mainly in a shorthand form. For example, the form P2 \& P3 \& P4 \& $\mathbf{u}_{72}$ is indicating the optimization of $\mathrm{TI}_{\text {new }}=\mathrm{k}_{2} \times \mathbf{P} 2\left(\mathrm{a}_{2}, \mathrm{~b}_{2}, \mathrm{c}_{2}\right)+\mathrm{k}_{3} \times \mathbf{P} 3\left(\mathrm{a}_{3}, \mathrm{~b}_{3}, \mathrm{c}_{3}, \mathrm{~d}_{3}\right)+\mathrm{k}_{4} \times \mathbf{P} \mathbf{4}\left(\mathrm{a}_{4}\right.$, $\left.\mathrm{b}_{4}, \mathrm{c}_{4}, \mathrm{~d}_{4}, \mathrm{e}_{4}\right)+\mathrm{k}_{72} \times \mathbf{u}_{72}\left(\mathrm{a}_{72}, \mathrm{~b}_{72}, \mathrm{c}_{72}\right)$.

The values of exponents $a, b, \ldots$ and the value of the smallest of the factors $k$ are taken here generally to have two significant digits. When a different number of significant digits is employed, this is explicitly mentioned. When necessary, one decimal more is used than the number of significant digits, for example 0.092 in the case of two significant digits or 0.0921 in the case of three significant digits.

As measures for the goodness of the linear correlation the following are used: the correlation coefficient $R$, the standard error $S$ and the information content regarding the influence of branching ${ }^{14}$ IC. In most cases only the correlation coefficient $R$ is given. The software for statistics calculations included in the program package MS Excel was used.

The values of boiling points of octanes were taken from $\mathrm{Li}^{15}$ converting ${ }^{\circ} \mathrm{C}$ to $\mathrm{K}$, ref. ${ }^{14}$ Appendix 1 .

\section{Results and Discussion}

The aim of this paper is to demonstrate in the case of the boiling points of octanes the way of how to proceed to develop the best possible descriptors using the vertex-degree weighted path indices in combination with the vertex-degree vertex-distance weighted elements of the Universal matrix.

In the first step, the values of exponents in individual vertex-degree weighted path indices as well as vertex-degree vertex-distance weighted elements of the Universal matrix are optimized. For the individual vertex-degree weighted path indices this is demonstrated in Table 1 . The same should be done for the individual vertex-degree vertex-distance weighted elements of the Universal matrix. The best-observed values of the correlation coefficient $R$ between optimized individual vertex-degree vertex-distance weighted elements of the Universal matrix and the boiling point of octanes using two significant digits in their exponents are $-0.82<R<-0.88$, thus between those of $\mathbf{P 2}$ and $\mathbf{P} 4$ in Table 1.

In the second step, the mutually optimized combinations of two of them should be made. The best results for vertex-degree weighted path indices are presented in Table 2.

The best individual result gives the vertex-degree weighted path three index P3(-0.9739, -1.3213, -1.667, $-0.1944)$ with $R<0.95$ as presented in Table 1 . In the mu-
Table 1. The values of the correlation coefficient $R$ between optimized individual vertex-degree weighted path indices and the boiling point of octanes as a function of the number of significant digits in their exponents. In bold: the best of them.

\begin{tabular}{lcccc}
\hline $\begin{array}{l}\text { Significant } \\
\text { digits }\end{array}$ & P1 & P2 & P3 & P4 \\
\hline grid $^{14}$ & -0.8961 & -0.9083 & 0.9127 & 0.7967 \\
one & -0.8961 & -0.9095 & 0.9424 & 0.7970 \\
two & -0.9125 & -0.9107 & 0.9433 & 0.7973 \\
three & -0.9161 & -0.9107 & 0.9433 & 0.7974 \\
four & -0.9175 & -0.9107 & $\mathbf{0 . 9 4 3 3}$ & 0.7974 \\
\hline
\end{tabular}

Table 2. The goodness of correlation between mutually optimized combinations of the vertex-degree weighted path indices and the boiling point of octanes.

\begin{tabular}{llccc}
\hline TI $_{\text {new }}$ & \multicolumn{1}{c}{$\boldsymbol{R}$} & $\boldsymbol{S}$ & $\boldsymbol{I C}(\boldsymbol{\%})$ & Sign. dig. \\
\hline P2 \& P3 & 0.9797 & 1.266 & 79.9 & 2 \\
& 0.9804 & 1.241 & 80.3 & 3 \\
P2 \& P4 & 0.9926 & 0.767 & 87.8 & 2 \\
& $\mathbf{0 . 9 9 2 8}$ & 0.755 & 88.0 & 3 \\
P3 \& P4 & 0.9803 & 1.246 & 80.3 & 2 \\
& 0.9870 & 1.013 & 83.9 & 3 \\
P2 \& P3 \& P4 & 0.9956 & 0.588 & 90.7 & 2 \\
& $\mathbf{0 . 9 9 9 5 0}$ & 0.202 & 96.8 & 3 \\
P1 \& P2 \& P3 \& P4 & 0.999579 & 0.183 & 97.1 & 2 \\
& $\mathbf{0 . 9 9 9 7 6 3}$ & 0.137 & 97.8 & 3 \\
\hline
\end{tabular}

Sign. dig. - No. of significant digits in exponents $a, b, \ldots$ and the smallest factor $\mathrm{k}$ In bold - The best of that group

tually optimized combination of two of vertex-degree weighted path indices (Table 2) the best result is observed using the vertex-degree weighted path indices P2 \& P4 in the form $\mathrm{TI}_{\text {new }}=-0.519 \times \mathbf{P} 2(-0.421,-0.408,-0.304)$ $-0.481 \times \mathbf{P} 4(0.364,-0.075,-0.728,-0.705,-\infty)$ giving rise to $R>0.99$.

The procedure is continued including additional vertex-degree weighted path indices or vertex-degree vertex-distance weighted elements of the Universal matrix.

The mutually optimized combination of four vertex-degree weighted path indices using two significant digit values in exponents and the smallest factor $\mathrm{k}$ in the form of $\mathrm{TI}_{\text {new }}=\mathbf{P 1} \& \mathbf{P 2}$ \& P3 \& P4 $\equiv \mathrm{k}_{1}{ }^{\star} \mathbf{P 1}\left(\mathrm{a}_{1}, \mathrm{~b}_{1}\right)+$ $\mathrm{k}_{2}{ }^{\star} \mathbf{P} 2\left(\mathrm{a}_{2}, \mathrm{~b}_{2}, \mathrm{c}_{2}\right)+\mathrm{k}_{3}{ }^{\star} \mathbf{P} 3\left(\mathrm{a}_{3}, \mathrm{~b}_{3}, \mathrm{c}_{3}, \mathrm{~d}_{3}\right)+\mathrm{k}_{4}{ }^{\star} \mathbf{P} 4\left(\mathrm{a}_{4}, \mathrm{~b}_{4}, \mathrm{c}_{4}, \mathrm{~d}_{4}\right.$, $\left.\mathrm{e}_{4}\right)$ is $\mathrm{TI}_{\text {new }}=-0.0033 \times \mathbf{P 1}(-0.40,1.88)-0.6537 \times \mathbf{P} 2(-0.087$, $-0.68,-0.007)-0.2947 \times \mathbf{P 3}(0.004,-0.56,-1.89,-7.3)$ $-0.0483 \times \mathbf{P} 4(0.45,-0.005,-0.52,0.28,0.91)$, giving rise to $R=0.999579, S=0.183, I C=97.1 \%$.

Using three significant digits, it is $\mathrm{TI}_{\text {new }}=$ $-0.0257 \times \mathbf{P 1}(-0.1799,1.595)-0.6522 \times \mathbf{P} 2(-0.0266,-0.680$, $-0.0233)-0.2759 \times \mathbf{P 3}(0.0266,-0.618,-1.876,-\infty)$ $-0.0462 \times \mathbf{P} 4(0.457,-0.0966,-0.535,0.278,1.076)$ giving rise to $R=0.999763, S=0.137, I C=97.8 \%$. This demonstrates that it is advisable to use at least two or, even better, three significant digits. 
The mutually optimized combinations of a vertex-degree weighted path index with particular vertex-degree vertex-distance weighted elements of the Universal matrix are presented in Figure 1 for $\mathbf{P 2}\left(\mathrm{a}_{2}, \mathrm{~b}_{2}, \mathrm{c}_{2}\right)$. For the vertex-degree weighted path indices $\mathbf{P} \mathbf{1}\left(\mathrm{a}_{1}, \mathrm{~b}_{1}\right), \mathbf{P} 3\left(\mathrm{a}_{3}, \mathrm{~b}_{3}\right.$, $\left.c_{3}, d_{3}\right)$, and $\mathbf{P} 4\left(a_{4}, b_{4}, c_{4}, d_{4}, e_{4}\right)$ they are presented in Appendix 2 .

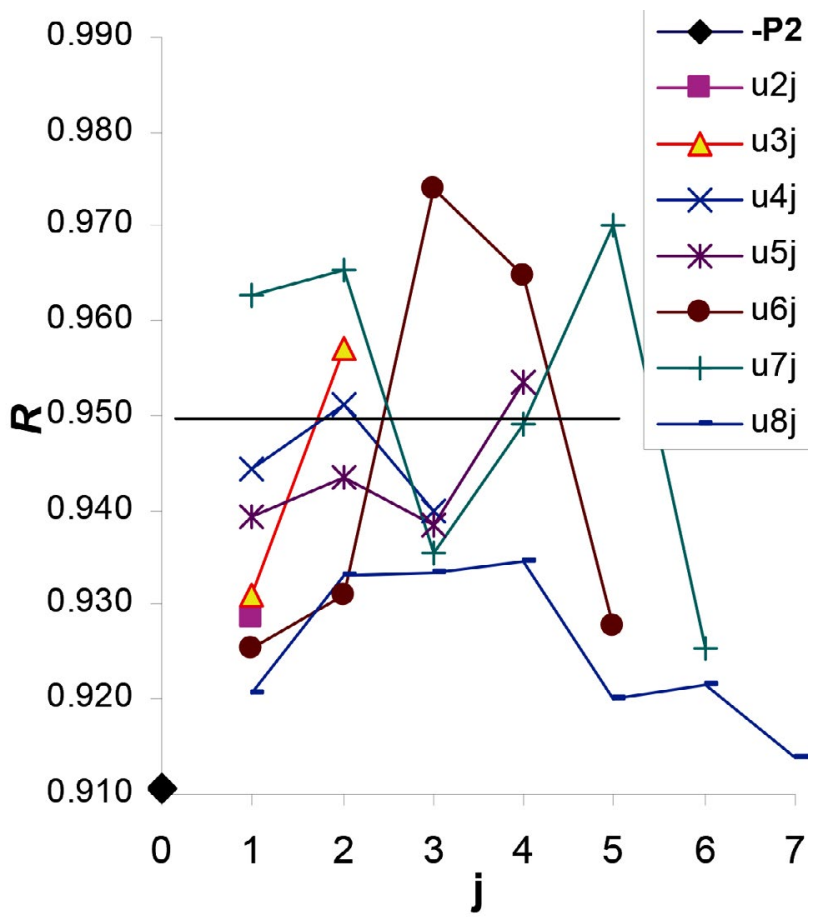

Figure 1. Correlation coefficients of the mutually optimized combinations of the vertex-degree weighted path two index with vertex-degree vertex-distance weighted elements of the Universal ma$\operatorname{trix} \mathbf{u}_{\mathrm{ij}}\left(\mathrm{a}_{\mathrm{ij}}, \mathrm{b}_{\mathrm{ij}}, \mathrm{c}_{\mathrm{ij}}\right)$.

As can be seen in Figure 1 and in additional Figures in Appendix 2, some of the vertex-degree vertex-distance weighted elements of the Universal matrix improve substantially the goodness of correlation obtained by the individual vertex-degree weighted path indices.

In combinations of one vertex-degree weighted path index with one vertex-degree vertex-distance weighted element of the Universal matrix the most promising are on average the matrix elements $\mathbf{u}_{63}\left(a_{63}, b_{63}, c_{63}\right), \mathbf{u}_{75}\left(a_{75}, b_{75}\right.$, $\left.c_{75}\right), \mathbf{u}_{32}\left(a_{32}, b_{32}, c_{32}\right), \mathbf{u}_{71}\left(a_{71}, b_{71}, c_{71}\right), \mathbf{u}_{72}\left(a_{72}, b_{72}, c_{72}\right)$, and $\mathbf{u}_{53}\left(\mathrm{a}_{53}, \mathrm{~b}_{53}, \mathrm{c}_{53}\right)$.

Table 3 demonstrates that some of the vertex-degree vertex-distance weighted elements of the Universal matrix improve the optimized combination of the vertex-degree weighted path indices P2 \& P3 \& P4 better than the vertex-degree weighted path one index.

The best of them is $\mathrm{TI}_{\text {new }}=\mathbf{P} 2 \& \mathbf{P} 3 \& \mathbf{P} \mathbf{4} \& \mathbf{u}_{\mathbf{7 2}} \equiv$ $\mathrm{k}_{2}{ }^{\star} \mathbf{P} 2\left(\mathrm{a}_{2}, \mathrm{~b}_{2}, \mathrm{c}_{2}\right)+\mathrm{k}_{3}{ }^{*} \mathbf{P} \mathbf{3}\left(\mathrm{a}_{3}, \mathrm{~b}_{3}, \mathrm{c}_{3}, \mathrm{~d}_{3}\right)+\mathrm{k}_{4}{ }^{*} \mathbf{P} 4\left(\mathrm{a}_{4}, \mathrm{~b}_{4}, \mathrm{c}_{4}, \mathrm{~d}_{4}\right.$, $\left.\mathrm{e}_{4}\right)+\mathrm{k}_{72}{ }^{*} \mathbf{u}_{72}\left(\mathrm{a}_{72}, \mathrm{~b}_{72}, \mathrm{c}_{72}\right)=-0.69059^{*} \mathbf{P 2}(-0.0132,-0.675$, $0.0435)-0.04476^{\star} \mathbf{P} 4(0.404,0.0793,-0.498,0.288,1.106)$
Table 3. The best observed results in the mutually optimized combinations of vertex-degree weighted path indices with the vertex-degree vertex-distance weighted elements of the Universal matrix in relation to the boiling points of octanes using three significant digits.

\begin{tabular}{|c|c|c|c|}
\hline & $\boldsymbol{R}$ & $S$ & IC (\%) \\
\hline P2 \& P3 \& P4 \& $u_{72}$ & 0.99988 & 0.098 & 98.5 \\
\hline P2 \& P3 \& P4 \& $u_{76}$ & 0.99983 & 0.115 & 98.2 \\
\hline P2 \& P3 \& P4 \& $u_{62}$ & 0.99983 & 0.117 & 98.1 \\
\hline P2 \& P3 \& P4 \& $\mathbf{u}_{74}$ & 0.99981 & 0.123 & 98.0 \\
\hline $\mathrm{P} 2 \& \mathrm{P} 3 \& \mathrm{P} 4 \& \mathrm{u}_{52}$ & 0.99978 & 0.133 & 97.9 \\
\hline $\mathrm{P} 2 \& \mathrm{P} 3$ \& P4 \& P1 & 0.99976 & 0.137 & 97.8 \\
\hline P2 \& P3 \& P4 & 0.99950 & 0.199 & 96.8 \\
\hline
\end{tabular}

$-0.25706{ }^{\star} \mathbf{P 3}(-0.1118, \quad-0.601, \quad-1.905, \quad-2.53)$ $-0.00759^{*} \mathbf{u}_{72}(-2.08,1.137,0.0315)$ giving rise to $R=$ $0.99988, S=0.098, I C=98.5 \%$. Its values are presented in Table 4 . In the case of octane isomers its values are not degenerated.

Table 4. Values of the descriptor $\mathrm{TI}_{\text {new }}=\mathbf{P} 2 \& \mathbf{P} 3 \& \mathbf{P} 4 \& \mathbf{u}_{72}$ rounded to five decimals.

\begin{tabular}{lc}
\hline Octane & TI $_{\text {new }}$ \\
\hline Oct & -3.09185 \\
2M7 & -3.19772 \\
3M7 & -3.18390 \\
4M7 & -3.20116 \\
3Et6 & -3.18612 \\
25M6 & -3.31415 \\
24M6 & -3.31140 \\
23M6 & -3.22836 \\
34M6 & -3.19898 \\
3Et2M5 & -3.22757 \\
22M6 & -3.34633 \\
33M6 & -3.27560 \\
3Et3M5 & -3.19138 \\
234M5 & -3.25649 \\
224M5 & -3.44826 \\
223M5 & -3.30526 \\
233M5 & -3.23618 \\
2233M4 & -3.35245 \\
\hline
\end{tabular}

But one should not forget that the values of the descriptor $\mathrm{TI}_{\text {new }}=\mathbf{P} 2 \& \mathbf{P} 3 \& \mathbf{P} \mathbf{4} \& \mathbf{u}_{\mathbf{7 2}}$ are good in relation to the boiling points of octanes. For other properties of octanes, some different mutually optimized combinations of vertex-degree weighted path indices with the vertex-degree vertex-distance weighted elements of the Universal matrix are to be developed in the way demonstrated above.

One of the earliest descriptor combinations used was the combination of the Wiener index $(\mathrm{W})$ with the path three index $\left(\mathrm{p}_{3}\right)^{3,4}$ Correlations in combinations of descriptors $\mathrm{p}_{3}$ and $\mathrm{W}$ are presented in Table 5 . 
Table 5. Correlations of the combinations of descriptors $\mathrm{p}_{3} \& \mathrm{~W}$ with the boiling points of octanes $\left(\mathrm{TI}_{\text {new }}=\mathrm{k}_{3}{ }^{*} \mathrm{p}_{3}+\mathrm{k}_{\mathrm{w}}{ }^{*} \mathrm{~W} ; \mathrm{k}_{3}+\mathrm{k}_{\mathrm{w}}=1\right)$.

\begin{tabular}{lccc}
\hline & $\boldsymbol{R}$ & $\boldsymbol{S}$ & $\boldsymbol{I C}(\mathbf{\%})$ \\
\hline $\mathrm{k}_{3}=\mathrm{k}_{\mathrm{W}}=0.5$ & 0.6740 & 4.660 & 26.1 \\
optimized $\mathrm{k}_{3}{ }^{*}$ & 0.9888 & 0.943 & 85.1 \\
optimized $\mathrm{k}_{3}{ }^{*}$ & 0.9892 & 0.926 & 85.3 \\
\hline
\end{tabular}

${ }^{*}$ two significant digits ${ }^{* *}$ three significant digits

They are not as good as in the mutually optimized combination of P2 \& P4 \& P3 \& $\mathbf{u}_{72}$. In comparison of optimized combinations $\mathrm{p}_{3} \& \mathrm{~W}$ vs. P2 \& P4 \& P3 \& $\mathbf{u}_{72}$ it is $R=0.9892$ vs. $0.99988, S=0.926$ vs. 0.098 , and $I C(\%)=$ 85.3 vs. 98.5 .

The results of the optimized combinations of vertex-degree weighted path indices with the indices $\mathrm{W}, 7,8$ RW, ${ }^{16}$ and $\chi,{ }^{5}$ are presented in Table 6 . For comparison, the goodness of the correlation of the optimized combination of indices $\mathrm{W},{ }^{7,8} \mathrm{RW},{ }^{16}$ and $\chi,{ }^{5}$ is $R=0.9565, S=1.840$.

Table 6. Best correlations with boiling points of octanes of the combinations of indices $\mathrm{W}, \mathrm{RW}$, and $\chi$ with the optimized vertex-degree weighted path indices, $R(\mathrm{BP}, \mathbf{P N})$, using two significant digits in factors $\mathrm{k}$ and exponents. In bold: $R>0.95$.

\begin{tabular}{lccc}
\hline PN \&: & W & RW & $\boldsymbol{\chi}$ \\
\hline P1 & 0.9421 & 0.9175 & 0.9142 \\
P2 & 0.9124 & 0.9174 & 0.9295 \\
P3 & $\mathbf{0 . 9 8 9 2}$ & $\mathbf{0 . 9 6 9 6}$ & 0.9447 \\
P4 & 0.7990 & 0.7976 & 0.8609 \\
\hline
\end{tabular}

Best correlation with BP of the optimized combination of index $\mathrm{W}$ with the vertex-degree weighted path three index $\mathbf{P} 3\left(\mathrm{a}_{3}, \mathrm{~b}_{3}, \mathrm{c}_{3}, \mathrm{~d}_{3}\right)$ taking three significant digits in factors $\mathrm{k}$ and exponents, is: $R=0.9931, S=0.738, I C=88.3$ (\%).

The goodness of correlations presented here in Table 3 is, regarding $S$, between one and two orders of magnitude better than those presented in Tables 4-7.

Table 7. Goodness of correlation of descriptor combinations with the boiling point data of octanes

\begin{tabular}{|c|c|c|c|}
\hline Author(s) Ref. & No. of indices & $R$ & $S$ \\
\hline Ivanciuc et al. ${ }^{17}$ & 3 & 0.994 & 2.79 \\
\hline Ivanciuc et al. ${ }^{18}$ & 2 & 0.984 & 4.94 \\
\hline Randić ${ }^{19}$ & 2 & 0.914 & 2.56 \\
\hline This work & 4 & 0.99988 & 0.098 \\
\hline
\end{tabular}

The goodness of correlation of individual path/walk indices ${ }^{19}$ with boiling point data of octanes is low, $|R|<$ $0.71, S>4.5$. The goodness of $R>0.9$ and $S<2.6$ gives the optimized combination of $\mathrm{p}_{2} / \mathrm{w}_{2} \& \mathrm{p}_{3} / \mathrm{w}_{3},{ }^{19}$ Table 7 . Comparing it to $\mathrm{p}_{2} \& \mathrm{p}_{3}(R=0.919, S=2.49)$ it is a slightly less good descriptor for the boing point of octanes, and comparing it to P2 \& P3, Table 3, $(R=0.9797, S=1.266)$ it is much less good.

Better than $\mathrm{p}_{2} / \mathrm{w}_{2} \& \mathrm{p}_{3} / \mathrm{w}_{3},{ }^{19}$ are the optimized combinations $\mathrm{p}_{2} / \mathrm{w}_{2} \& \mathrm{p}_{3} / \mathrm{w}_{3} \& \mathrm{p}_{5} / \mathrm{w}_{5}(R=0.9206, S=2.463)$ and $\mathrm{p}_{2} / \mathrm{w}_{2} \& \mathrm{p}_{3} / \mathrm{w}_{3} \& \mathrm{p}_{4} / \mathrm{w}_{4}(R=0.9780, S=1.315)$. Comparing the latter to $\mathrm{p}_{2} \& \mathrm{p}_{3} \& \mathrm{p}_{4}(R=0.9674, S=1.598)$ indicates that the combinations of the path/walk indices are more promising than the combinations of the path indices. Comparing to P2 \& P3 \& P4, Table 3, $(R=0.99950$, $S=0.202)$, the optimized combination of $\mathrm{p}_{2} / \mathrm{w}_{2} \& \mathrm{p}_{3} / \mathrm{w}_{3} \&$ $\mathrm{p}_{4} / \mathrm{w}_{4}$ is much less good than the corresponding optimized combination of the vertex-degree weighted path indices.

The optimized combination of four path/walk indices of octanes, $\mathrm{TI}_{\text {new }}=\sum \mathrm{k}_{\mathrm{i}} \times \mathrm{p}_{\mathrm{i}} / \mathrm{w}_{\mathrm{i}}=\mathrm{k}_{2}{ }^{*} \mathrm{p}_{2} / \mathrm{w}_{2}+\mathrm{k}_{3}{ }^{*} \mathrm{p}_{3} / \mathrm{w}_{3}+$ $\mathrm{k}_{4}{ }^{*} \mathrm{p}_{4} / \mathrm{w}_{4}+\mathrm{k}_{5}^{*} \mathrm{p}_{5} / \mathrm{w}_{5}=-0.403^{*} \mathrm{p}_{2} / \mathrm{w}_{2}+0.115^{*} \mathrm{p}_{3} / \mathrm{w}_{3}$ $-0.305^{\star} \mathrm{p}_{4} / \mathrm{w}_{4}-0.177^{\star} \mathrm{p}_{5} / \mathrm{w}_{5}$ gives rise to $R=0.9883, S=$ 0.962 , which is better than the optimized combination of $\mathrm{p}_{2} \& \mathrm{p}_{3} \& \mathrm{p}_{4} \& \mathrm{p}_{5}(R=0.9780, S=1.317)$ and slightly better than the combination P3 \& P4, Table 2.

Among the vertex-degree vertex-distance weighted elements of the Universal matrix, which improve the correlation of P2 \& P3 \& P4 more than P1, Table 3, there are $\mathbf{u}_{\mathbf{7 2}}>\mathbf{u}_{\mathbf{7 6}}>\mathbf{u}_{\mathbf{7 4}}$ and $\mathbf{u}_{\mathbf{7 2}}>\mathbf{u}_{\mathbf{6 2}}>\mathbf{u}_{\mathbf{5 2}}$. In the five vertex-degree vertex-distance weighted elements of the Universal matrix, which improve the correlation of P2 \& P3 \& P4 better than P1, there appear the vertices No. 2 and No. 7 three times each, vertex No. 6 two times, and vertices No. 4 and 5 once. Thus, the vertices No. 2 and 7 contribute the larger part of the improvement, whereas the vertices No. 4, 5, and 6 contribute less.

The structural interpretation of the contribution of vertices No. 2, 4, 5, 6, and 7 can be based on two criteria, i.e. whether they are interior or peripheral vertices. The interior vertices are either bearing the branches and they are thus contributing the information about the branching of octanes or they are exposed to intermolecular contacts, which are modified by the sterical hindrance of neighbouring branches. The peripheral vertices are exposed to and modifying the intermolecular contacts.

For illustration is presented the structure of 2,3-dimethylhexane:

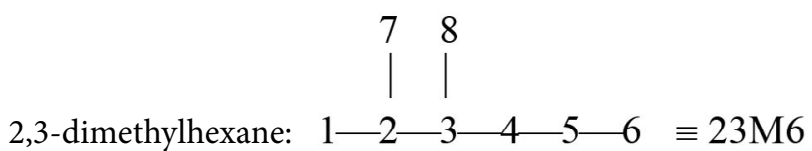

In 2,3-dimethylhexane, the vertices No. 1, 6, 7, and 8 are of degree one, the vertices No. 4 , and 5 are of degree two, the vertices No. 2 and 3 are of degree three, whereas there is no vertex of degree four.

Among octane isomers, the vertices No. 1 and 8 are in all cases peripheral. The vertex No. 2 is in all cases an interior vetrex. By the IUPAC Chemical Nomenclature 
used here for the enumeration of vertices, the vertex No. 2 is of degree two in 7 out of 18 cases, of degree three in 7 out of 18 cases as well, and of degree four in 4 out of 18 cases. The same holds true for the vertex No. 3. They are bearing the majority of the information about branching of octanes. However, the vertex-degree vertex-distance weighted elements of the Universal matrix containing the vertex No. 3 give rise to $R$ between 0.9995 and 0.9996 and $S$ between 0.199 and 0.177 , whereas the vertex-degree vertex-distance weighted elements of the Universal matrix containing the vertex No. 2 mentioned in Table 3 give rise to $R$ between 0.99978 and 0.99988 and $S$ between 0.133 and 0.098 .

The vertex No. 4 is peripheral in one case only, when it is of degree one. In other cases, it is an interior vertex. It is of degree two in 12 out of 18 cases, of degree three in 5 out of 18 cases, and in no case it is of degree four.

The vertex No. 5 is interior in 11 out of 18 cases, whereas it is peripheral in 7 out of 18 cases. It is of degree three in one case only.

The vertex No. 6 is peripheral in 14 out of 18 cases and when interior, it is of degree two only.

The vertex No. 7 is of degree one among all octanes with the exception of $n$-octane, thus in 17 out of 18 cases. It is thus mainly a peripheral vertex exposed to intermolecular contacts and modifying them.

The boiling point is dependent on intermolecular attraction. Among octanes, it is dependent on attraction and repulsion between the structural groups $\mathrm{C}, \mathrm{CH}, \mathrm{CH}_{2}$, and $\mathrm{CH}_{3}$, i.e. speaking in terms of mathematical chemistry, between vertices of degree four, three, two and one. Whereas at the equilibrium distance the contribution to attraction between equal functional groups is $\mathrm{C}>\mathrm{CH}>\mathrm{CH}_{2}>\mathrm{CH}_{3}$, its dependence on intermolecular distance $\mathrm{d}$ is $\mathrm{d}^{-6} \cdot{ }^{20}$ The interplay of different contribution to attraction by structural groups, which are represented in topological indices by vertices of different degrees, and of different distances between them in different liquid octane isomers, contributes to differences in boiling points of octane isomers. The structural interpretation of the contribution of different vertices reflects this interplay.

The differences between the experimental data of the boiling points of octanes and the calculated ones using combinations presented in Table 3 are shown in Figure 2.

In Figure 2 we see that in the optimized combination of vertex-degree weighted path indices P2 \& P3 \& P4 the difference between the experimental data and the calculated ones is larger than $0.1 \mathrm{~K}$ at octane isomers n-octane, 2-methylheptane, 3-methylheptane, 2,4-dimethylhexane, 2,3-dimethylhexane, 3-ethyl-2-methylpentane, as well as among all octanes having three resp. four branches. In the best observed case, the optimized combination of P2 \& P3 \& $\mathbf{P} 4 \& \mathbf{u}_{72}$, the difference between the experimental data and the calculated ones is larger than $0.1 \mathrm{~K}$ at octane isomers 2-methylheptane, 4-methylheptane, 3-ethylhexane, 2,3,3-trimethylpentane, and 2,2,3,3-tetramethylbutane.

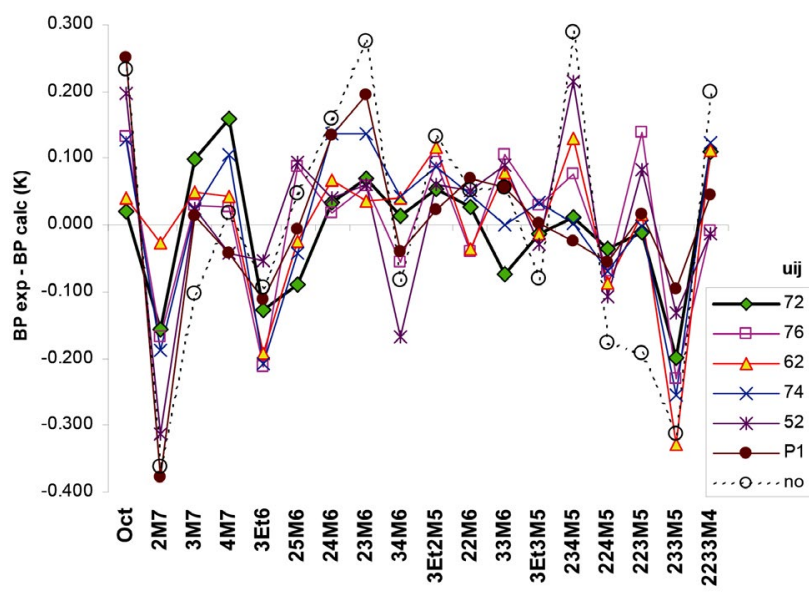

Figure 2. Differences between the experimental data of the boiling points of octanes and the calculated ones using correlations with P2 \& P3 \& P4 \& $u_{i j}$.

If we compare the results observed here in the mutually optimized combination of P2 \& P3 \& P4 \& $\mathbf{u}_{72}$ with those reported by some other authors using more than one variable in their equations, ${ }^{17-19}$ we can see that the results obtained here are better than those by using other models with several (2 to 3 ) other indices at once.

As a conclusion it can be said that the mutually optimized combinations of the vertex-degree weighted path indices and the vertex-degree vertex-distance weighted elements of the Universal matrix in the form of $\mathrm{TI}_{\text {new }}=$ $\sum \mathrm{k}_{\mathrm{N}} \times \mathbf{P N}\left(\mathrm{a}_{\mathrm{N}}, \mathrm{b}_{\mathrm{N}}, \ldots\right)+\mathrm{k}_{\mathrm{ij}} \times \mathbf{u}_{\mathrm{ij}}\left(\mathrm{a}_{\mathrm{ij}}, \mathrm{b}_{\mathrm{ij}}, \mathrm{c}_{\mathrm{ij}}\right)$ give rise in the case of the boiling points of octanes up to $R=0.99988, S=$ $0.098, I C=98.5 \%$ and similar combinations are thus promising indices also of other properties. That the approach demonstrated here in detail is generally applicable has been shown previously for the mutually optimized combinations of the vertex-degree vertex-distance weighted elements of the Universal matrix ${ }^{14}$ as well as for the mutually optimized combinations of vertex-degree weighted path indices. ${ }^{9}$ There can be seen that at different physicochemical properties of octanes different mutually optimized combinations of the vertex-degree weighted path indices, ${ }^{9}$ respectively the vertex-degree vertex-distance weighted elements of the Universal matrix ${ }^{14}$ give rise to the best correlation.

\section{References}

1. J. R. Platt, J. Chem. Phys. 1947, 15, 419-420.

DOI:10.1063/1.1746554

2. M. Randić, J. Chem. Educ. 1992, 69, 713-718.

DOI:10.1021/ed069p713

3. H. Wiener, J. Am. Chem. Soc. 1947, 69, 17-20.

DOI:10.1021/ja01193a005

4. H. Wiener, J. Am. Chem. Soc. 1947, 69, 2636-2638. 
DOI:10.1021/ja01203a022

5. M. Randić, J. Am. Chem. Soc. 1975, 97, 6609-6615. DOI:10.1021/ja00856a001

6. M. Randić, C.L. Wilkins, J. Phys. Chem. 1979, 83, 1525-1540. DOI:10.1021/j100474a032

7. L. B. Kier, L. H. Hall, J. Pharm. Sci. 1976, 65, 1806-1809. DOI:10.1002/jps.2600651228

8. L. B. Kier, L. H. Hall, Molecular Connectivity in Structure-Activity Analysis, Willey, New York, 1986.

9. A. Perdih, Acta Chim. Slov. 2016, 63, 88-96.

DOI:10.17344/acsi.2015.1975

10. O. Ivanciuc, Rev. Roum. Chim. 1999, 44, 519-528.

DOI:10.1097/00006123-199903000-00054

11. O. Ivanciuc, Rev. Roum. Chim. 2000, 45, 587-596.

12. A. Perdih, B. Perdih, Acta Chim. Slov. 2004, 51, 598-609.
13. A. Perdih, F. Perdih, Acta Chim. Slov. 2006, 53, 180-190.

14. A. Perdih, Acta Chim. Slov. 2015, 62, 879-888. DOI:10.17344/acsi.2015.1607

15. X. H. Li, Chem. Phys. Lett. 2002, 365, 135-139. DOI:10.1007/978-3-322-99997-9_9

16. M.V. Diudea, J. Chem. Inf. Comput. Sci. 1997, 37, 292-299. DOI: $10.1021 / \mathrm{ci} 960037 \mathrm{w}$

17. O. Ivanciuc, T. Ivanciuc, A.T. Balaban, Internet Electron. J. Mol. Des. 2002, 1, 467-487.

18. O. Ivanciuc, T. Ivanciuc, D. Cabrol-Bass, A.T. Balaban, Internet Electron. J. Mol. Des. 2002, 1, 319-331.

19. M. Randić, J. Chem. Inf. Comput. Sci. 2001, 41, 607-613 DOI:10.1021/ci0001031

20. F. M. Fowkes, in R. L. Patrick, Ed., Treatise on Adhesion and Adhesives. Vol. 1: Theory, M. Dekker, New York, 1967, pp. 325-449.

\section{Povzetek}

Uporabljene so bile kombinacije uteženih indeksov poti in uteženih elementov Univerzalne matrike, optimirane na način $\mathrm{TI}_{\text {novi }}=\sum \mathrm{k}_{\mathrm{N}} \times \mathbf{P N}\left(\mathrm{a}_{\mathrm{N}}, \mathrm{b}_{\mathrm{N}}, \ldots\right)+\mathrm{k}_{\mathrm{ij}} \times \mathbf{u}_{\mathrm{ij}}\left(\mathrm{a}_{\mathrm{ij}}, \mathrm{b}_{\mathrm{ij}}, \mathrm{c}_{\mathrm{ij}}\right)$. Korelirane so bile $\mathrm{z}$ vrelišči oktanov. Kombinacije uteženih indeksov poti P2 $\left(a_{2}, b_{2}, c_{2}\right), \mathbf{P 3}\left(a_{3}, b_{3}, c_{3}, d_{3}\right)$ in $\mathbf{P 4}\left(a_{4}, b_{4}, c_{4}, d_{4}, e_{4}\right)$ so dale korelacijo $R=0.99950$. Ko so bili poleg uteženih indeksov poti P2 $\left(\mathrm{a}_{2}, \mathrm{~b}_{2}, \mathrm{c}_{2}\right), \mathbf{P 3}\left(\mathrm{a}_{3}, \mathrm{~b}_{3}, \mathrm{c}_{3}, \mathrm{~d}_{3}\right)$ in P4 $\left(\mathrm{a}_{4}, \mathrm{~b}_{4}, \mathrm{c}_{4}, \mathrm{~d}_{4}, \mathrm{e}_{4}\right)$ uporabljeni tudi P1 $\left(\mathrm{a}_{1}, \mathrm{~b}_{1}\right)$ ali $\mathbf{u}_{72}\left(\mathrm{a}_{72}, \mathrm{~b}_{72}, \mathrm{c}_{72}\right)$ ali $\mathbf{u}_{76}\left(\mathrm{a}_{76}, \mathrm{~b}_{76}, \mathrm{c}_{76}\right)$ ali $\mathbf{u}_{62}\left(\mathrm{a}_{62}, \mathrm{~b}_{62}, \mathrm{c}_{62}\right)$ ali $\mathbf{u}_{74}\left(\mathrm{a}_{74}, \mathrm{~b}_{74}, \mathrm{c}_{74}\right)$ ali $\mathbf{u}_{52}\left(\mathrm{a}_{52}, \mathrm{~b}_{52}, \mathrm{c}_{52}\right)$, so dali $R$ do $0.99988, S$ do $0.098, I C$ do $98.5 \%$. Optimirane kombinacije uteženih indeksov poti in uteženih elementov Univerzalne matrike so obetajoči indeksi tudi za druge fizikokemijske lastnosti oktanov.

Except when otherwise noted, articles in this journal are published under the terms and conditions of the Creative Commons Attribution 4.0 International License 